tached, and between 1 P.M. and 10 P.M.: when the boy pulled out the tube, 6 pints $14 \mathrm{oz}$. had drained away. He was much relieved. He was ordered two drachms of the resinof-copaiba mixture, and to this some tincture of digitalis was subsequently added. Notwithstanding this the abdomen filled again. He was now tapped again in the same way as before, the cannula being left in the peritoneal cavity for forty-eight hours. Ten pints of fluid had drained away, the latter part of it containing a little thick ropy sediment. $\mathrm{He}$ had complained of a little pain during the last few hours, which was to be attributed, I think, to the fact that the peritoneum had become emptied of its fluid, and the cannula consequently rubbed against the intestinal coils. He had no other adverse symptom from the operation.

CASE 3.- Mary F-, with general anasarea and ascites, the result of capillary bronchitis and distension of the right side of the heart, was admitted under Dr. Moxon's care, and it ultimately became necessary to tap the abdomen. A capillary tube was introduced, as in the preceding cases, and the peritoneum drained for about twenty-four hours. Nine pints of fluid were obtained in that time. She has been relieved, and has suffered no inconvenience from the operation.

CASE 4.-Benjamin $\mathrm{H}-$, aged twenty-six, came as an out-patient, with ascites to such an extent that he was unable to walk upright from the pain the abdominal distension gave him. He had also double pleurisy, and from this and other reasons the case was considered to be one of tubercular disease of the serous membranes. He was admitted under Dr. Moxon, and paracentesis was at first performed in the ordinary way with a large trocar and cannula. He was much relieved, and left the hospital for a short time, after a long stay, for a convalescent home. He was then readmitted under my care in a similar state to that when he came first, the abdomen being again painfully distended. He was now tapped by a capillary cannula, and ten pints of fluid removed in the course of twenty-one hours, when the tube was witharawn. He was much relieved, and has suffered no inconvenience from the mode of tapping adopted.

This method of performing paracentesis abdominis will be sufficiently clear from a perusal of the cases. Dr. Southey's proposal for the treatment of anasarca is borrowed and applied to the treatment of fluid in the $a b$ dominal cavity- that is to say, a cannula of very fine bore is passed into the peritoneum, and, by means of a long drainage-tube attached to it, the fluid is slowly drained away. In the first instance the tubes made for the purpose of draining the subcutaneous cellular tissue were used, and they answered very well in that particular case ; but, doubting whether they would in all cases be long enough, $M r$. Hawksley made me some of additional length - one inch and a half, - but in all other respects after Dr. Southey's pattern. These have been in use since. The tubes have been retained in the abdomen for varying periods, but generally for about twenty-four hours, and it will not often be necessary to continue the drainage for a longer time than that. Should it be otherwise it would probably be better to withdraw the tube and insert another at some other spot.

Besides these cases of ascites, I have treated in a similar way a suppurating hydatid cyst in the lower part of the abdomen and an empyema. Both drained for a few hours very well, and the empyema was probably thoroughly drained ; the hydatid cyst, however, ceased to run, and other measures became necessary.

It is not to be expected that purulent fluids can often be treated advantageously by drainage through very minute tubes, and particularly in the chest, where the pus is liable to be thick. Still cases do occur in which such a plan is applicable, and there can be no harm in testing this as a preliminary measure. In pleuritic effusions of serous character slow drainage of this kind has, I think, several points in its favour, as compared with aspiration ; and in peritoneal effusions, in which we can calculate with considerable confidence upon the limpid nature of the fluid, the advantages of paracentesis performed in this way are sufficiently obvious to make it a wonder that it is not more usually adopted. I will enumerate these shortly.

In the first place, there is the difference in the severity of the operations. In the one case there is the incision through the skin, and then the passage of a large trocar. Both these stages, though not particularly painful, are, nevertheless, somewhat so, and, at any rate, unnecessarily so if a snaller operation will do as well. Paracentesis by a minute trocar and cannula is hardly more than the prick of a pin, and even a child does not mind it.

Secondly, the major operation is by no means free from the risk of peritonitis. I am not prepared at the moment to say in what percentage of cases of paracentesis after the usual fashion peritonitis is set up, but I know that the two conditions are frequently associated. Dr. Habershon, in 501 cases of peritonitis, gives fourteen as occurring after paracentesis. $^{1}$ It is nothing to the point to say, as may be said, that other predisposing causes coexist and should share the blame; or, rather, it is very much to the point as an argument in favour of reducing any additional risk to its lowest possible limit. It may yet be a question whether a small cannula lessens this risk, because what is gained by diminishing the size of the tube is lost, may be, by its prolonged retention. Still, there is prima facic evidence, derivable from experience in other parts of the body, which goes to show that a tube will remain as a syphon drain in an otherwise closed cavity for a long time without doing any mischief, and upon that point I entertain no doubt whatever. Thirdly, and this is the most important consideration of all, in the major operation the peritoneum is drained at once, and almost completely; in the minor, more or less of the fluid is removed gradually in the course of some hours. But except in occasional cases, where the respiration is urgently embarrassed, and immediate relief is necessary, it is not only not requisite, but probably it is harmful, to empty the peritoneal cavity suddenly. Shock is one of the risks usually said to attach to the operation of paracentesis abdominis, and that term would include a certain, though small, proportion of cases in which the sudden abstraction of many pints of fluid from the abdominal cavity interferes with the normal action of the heart, and syncope ensues; and another group in which the same abstraction of fluid so alters the condition of the circulation in the abdominal viscera that for the time being, and until this rights itself, there is more or less temporary stasis. All this is obviated by withdrawing the fluid slowly. But more than this, one of the main advantages of paracentesis is lost to us by this, our usual method. Under such circumstances, the operation is not, and cannot be, employed remedially. We perform paracentesis when we can no longer help it, to stave off some worse troubie. But surely there are many cases in which a timely withdrawal of a certain amount of fluid and careful attention to strapping and bandaging of the abdominal walls at the same time would be followed by permanent relief and sometimes by cure. Per contra, to empty the abdominal cavity at once is to favour the immediate transudation of so much more fluid, and to do away with the prospect of any than the most temporary benefit.

One caution is necessary in using small drainage-tubes, and this is that the difficulty of cleaning them is in inverse proportion to the diminution of their calibre; and they should, I think, always be placed in some boiling germicide, such as a solution of carbolic acid, before their introduction. Weymouth-street, W.

ON A CASE OF

RUPTURE OF THE QUADRICEPS EXTENSOR CRURIS IN BOTH LIMBS; OPERATION.

Br ROBERT ROXBURGH, M.B.\&c.,

LATE RESIDENT SLRGEON, ROYAL INFIRMARY, EDINBURGH, ETC.

J. D_, a labouring man, aged sixty-four, was admitted to the Edinburgh Infirmary, under the care of Professor Lister, on the 18th of May, 1877, complaining of weakmess in his lower limbs, and a constant tendency to fall. He stated that in February, 1873, he was knocked down by a cart, which he and some others were endeavouring to lift, and that while in the act of rising the shaft struck his right knee, which was flexed at the time, and immediately disabled him, so that he had to be assisted to his feet. He lay for a fortnight at his home, and applied fomentations to the injured limb. There was considerable swelling, and before it had quite subsided he returned to his work, but remained so lame as to require the use of a stick. In May, 1874, he stumbled, and, with a view to protecting the right and

1 Diseases of the Abdomen, Second Edition, p. 556. H 2 
enfeebled knee, he flexed his left knee, so as to fall on it. He was unable to rise, was carried to the hospital of the town where he resided, and lay there for a month, being treated, he said, for "rheumatics." Since leaving hospital he had been unable to work, and he came to Edinburgh to see whether anything could be done to improve his condition.

The patient was spare, and somewhat feeble-looking, pale, and of fair complexion. He was very deaf, but hearty in manner. On being asked to expose the limbs, the nature of his injuries at once became evident. The skin above the level of each patella was loose and wrinkled, and the upper edge of that bone hung prominently forward, so much so, indeed, that the fingers could easily be pushed down in the fold of skin between the knee-pan and the femur, and the outline of the articular surface of the latter could be distinctly felt. When the patient was seated in a chair, with the knees bent to a right angle, he could not extend them even in the smallest degree; but if one of his legs were passively extended, he was able to maintain it, and even to hold it up, in that position. If now the extended limb were slowly and gently flexed by the surgeon, it was seen that the power of bringing the limb back to the straight position remained till flexion had reached a certain point-viz., an angle of about 157 degrees, - when the leg suddenly dropped with a slight crack, and the patient was unable again to raise it. Closer observation showed that the whole attachment of the quadriceps to the patella was divided, the rectus being contracted upwards, and that the only portions of the muscle which remained functionally available were two lateral and posterior strands of the vasti, internal and external, which were attached to the fascia lata of the leg, and to the capsule of the knee-joint. When the limb was extended these portions of muscle were slightly anterior to the line of the limb, and consequently acted as extensors; but when the knee was flexed to an angle of about 157 degrees, they slipped back over the tuberosities of the femur, and immediately thereon came into play as flexors. When the knee was fully bent the outline of the trochlea of the femur was beautifully seen, having the skin stretched over it. The condition was almost precisely identical in both limbs.

As might have been expected under such circumstances, the man was very helpless. He could stand quite securely, but he scarcely dared move without a pair of sticks or crutches. His gait was shuffling, for he feared to bend his knees, and in going up a stair, he declared, be frequently fell, from the want of control over the movements of the knees, a statement which was confirmed by the numerous cicatrices on the skin over the joints.

Mr. Lister, knowing that if due care were exercised, the operation might be undertaken with safety to the patient, and hoping at least to render one limb more useful, resolved to try to rectify the condition. Accordingly, on June lst the patient was placed under the influence of chloroform, and after the skin of the part had been thoroughly cleansed with 1 in 20 carbolic lotion, a longitudinal incision was made on the front of the left limb, beginning at the lower border of the patella and extending upwards for about eight inches in the middle line of the thigh. The skin, fat, and fascia were then dissected up and turned aside, and the anterior borders of the vasti were exposed. The rectus tendon was not recognised, but the pale fibres of the atrophied muscle were found near the upper end of the incision. The upper border of the patella was then defined, and a longitudinal incision, corresponding to the primary one, was carried from it upwards through the fascia and muscular substance connecting the vasti across the front of the thigh. In doing this, the large bursa under the crureus was opened into. An incision was now made transversely from the lateral edge of the patella on either side into the substance of the vastus, and the portions of muscle so marked out were dissected as well as possible from the capsular ligament, and by longitudinal cuts with the knife from the deeper parts of the same muscles. In separating these portions of muscle from their connexions, the kneejoint was necessarily opened at several places. They were now brought into the middle line, and to effect this more easily, a wedge-shaped portion was removed from the mass of tissue representing the rectus and crurens. Their edges were stitched together by sutures of carbolised catgut, and their extremities fastened to the patella, through the medium of its fibrous covering, with the same material. Four counter-openings for drainage were now made at the most dependent parts-riz., where the displaced portions of the vasti muscles had lain, and drainage-tubes were inserted.
A few small articular branches were the only arteries which required ligature.

The incision was united, first by two wire-and-button sutures passed deeply through the tissues - "stitches of relaxation,"-and, secondly, the edges were approximated by carbolised silk stitches. At the lower end of the incision a drainage-tube of fine calibre was inserted. The operation was conducted antiseptically, and a large gauze dressing extending to the hip was applied. The limb was then bandaged to a well-padded posterior Gooch's splint.

On the evening of the operation the temperature was $99{ }^{\circ} 8^{\circ}$. June 2nd (the day after operation). - Patient had passed a good night, and breakfasted with relish. There being considerable serous oozing, the dressing was changed. Temperature : morning, $100^{\circ}$; evening, $101^{\circ}$. Pulse : morning, 104 ; evening, 92.

3rd.-Dressed. Temperature : morning, $99 \cdot 2^{\circ}$; evening, $100.4^{\circ}$. Pulse : morning, 104 ; evening, 86.

4th.-Dressed. Temperature : morning, $100 \cdot 2^{\circ}$; evening, $100 \cdot 2^{\circ}$. Pulse : morning, 88 ; evening, 100.

5th.- He complained of slight uneasiness in the limb. The wound was dressed, and seemed to look well. Temperature : morning, $100^{\circ}$; evening, $1002^{\circ}$. Pulse : morning, 88 ; evening, 100 .

6th.-There being no discharge visible beyond the dependent edge of the dressing, the limb for the first time was left undisturbed. Temperature : morning, $996^{\circ}$; evening, $99 \cdot 6^{\circ}$. Pulse : morning, 84; evening, 88.

7th.-Dressed. A degree of tension was apparent, and a few of the silk stitches were removed, when the wound gaped slightly at one place. Temperature : morning, $99^{\circ}$. Pulse : morning, 88. The patient seemed a little low, and was ordered a teaspoonful of compound tincture of quinine in a glass of sherry three times a day.

8th. -Dressed. Temperature : morning, $99^{\circ}$; evening, $99 \cdot 8^{\circ}$. Pulse: morning, 80 ; evening, 80.

9th.-Dressed. Temperature : morning, $98^{\circ}$; evening, $99 \cdot 6^{\circ}$, Pulse: morning, 84 ; evening, 80.

10th. - Not dressed. Temperature: morning, $98 \cdot 6^{\circ}$; evening, $100^{\circ}$. Pulse : morning, 80 ; evening, 80 .

11th.-Dressed. Temperature: morning, $98 \cdot 2^{\circ}$; evening, $98 \cdot 2^{\circ}$. Pulse : morning, 84; evening, 88 . At each dressing the tubes were removed, shortened, and cleansed in lotion before being returned.

12th.-Not dressed. Temperature: morning, $99^{\circ}$; evening, $100^{\circ}$. Pulse : morning, 88; evening, 84.

13th.-Dressed. The upper button-stitch was removed. A little pus on the dressing. Temperature : morning, $98 \cdot 2^{\circ}$; evening, $98 \cdot 6^{\circ}$.

16th--Since last note the wound had been diressed on alternate days. The skin seemed somewhat tumid, and one of the buttons of the lower button-suture was depressed below the level of the surrounding skin. A slight blush of redness was manifest in the edges of the wound at its lower part, while the presence of some pus in the deep dressing confirmed the other indications of tension. The button. suture was therefore relaxed.

17th.-Dressed. It was found that the lead-button, which yesterday had been pressing injuriously on the swollen tissues, had produced a superficial slough of the skin exactly corresponding with itself in size and shape. The whole suture was therefore at once removed. The drainage-tube at the lower part of the incision was now unnecessary, the wound having at that point opened up into an ulcer-like sore, and it was accordingly done away with.

20th.- The slough had now extended from its original position as far as the incision, and was about an inch and a quarter in length. The protective covering this slough had a dark stain and a fetid odour. Some bacterial forms could be distinguished with the microscope in the discharge. It was evident that putrefaction had taken place. As the temperature and pulse now remained normal, it was deemed unnecessary to continue registering them.

From this time healing proceeded steadily, but tardily. Towards the end of July, the gauze dressing was abandoned, and a simple dressing of moist boracic lint was substituted for it. It was now discovered that the patient had been in the habit of insinuating his hand under the upper part of the dressings to scratch his thigh, and doubtless atmospheric air had thus gained access to the neighbourhood of the wound, and set up putrefaction.

Aug. 1st.-The slongh had now disappeared, leaving a superficial granulating surface of small extent, which was cicatrising round the edges. 
Sept. 8th. - The wound had now been practically healed for several weeks, but the patient had been kept in bed with the leg bandaged to a posterior splint, to permit of thorough consolidation of the new textures before movement should be attempted. To-day the splint was removed, and he was allowed to get up a little.

Oct. 23rd.-The patient left the hospital.

The condition of the limb at the date of his discharge was as follows:-The outline of the knee was of almost normal appearance, with the exception of a depressed cicatrix about the size of a penny. The hollow above the patella had disappeared, and the skin here was tense, and covered firm muscle and tendon. The patella could be moved from side to side, but was very much less mobile than before the operation. When the patient lay on his back, and was asked to raise the limb into the air, he did so without difficulty, but it was noticeable that, preliminarily to the raising of the limb, the knee became slightly flexed, say to an angle of $157^{\circ}$, thus contrasting with the condition before operation, when it could only be raised from the bed in a rigidly straight position. Being now requested to bend the knee, he gradually permitted the limb to become flexed till it had reached an angle a little greater than a right angle, say $110^{\circ}$. This was the extreme limit of voluntary flexion. It was possible to increase this limit by force, but that would obviously have been an injudicious and useless proceeding. It was therefore evident that great benefit had resulted from the operation ; for whereas the patient had now complete control over the muscles of the knee between the angles of $157^{\circ}$ and $110^{\circ}$, it was precisely at the former of these angles that previously to the operation the vasti muscles had been wont to cease their action as extensors, and loss of control over the knee had ensued. So conscious was the patient of this improvement, and the increased safety and ease of progression which it favoured, that he declared that had he been a younger man he would have had no hesitation in asking Mr. Lister to operate on the other leg. As it was he felt that, being old and feeble, he might not have stamina enough to resist another serious operation, and resolved, perhaps wisely, to "let well alone." Before he left hospital a pair of poro-plastic, lateral splints were moulded to the right leg, and made to extend from well up the thigh to a little above the ankle. These were padded, and applied with straps. Their object was to prevent flexion of the knee during walking, and so to preclude the possibility of those sudden falls to which the patient had formerly been liable. A similar pair was made for the left limb, in case they should be of use, but he preferred not to wear them on that limb.

Remark on the above case (for the notes of which I am largely indebted to Mr. J. Stewart, M.B., the clinical clerk) seems almost superfluous. It speaks for itself. The case is a good example of the kind of operation which may be safely undertaken, and the kind of result which may be looked for, under antiseptic means. It may be affirmed without exaggeration that to cut down on a knee, expose the joint, remove the adjoining muscles from their existing connexions, and unite them by an organisable material to their proper place of attachment, is a proceeding which no surgeon would be justified in attempting under any other system but the antiseptic one; while the fact that this was followed in the present case by no injurious effects to the joint, and no greater constitutional disturbance than what is implied in a temporary rise of temperature to $100.2^{\circ}$ and a slight loss of appetite, proves that under that system such an operation can be undertaken with a degree of risk which is only to be measured inversely with the care exercised by the surgeon. To those who practise antiseptic surgery the case contains an important lesson-the extreme liability to putrefaction in a person of old and enfeebled tissues, and the almost exaggerated care which must be bestowed on the management of wounds in such an individual, where true antiseptic results are aimed at. It was a happy thing for our patient that the putrefaction which unfortunately did ultimately occur did not take place till nearly three weeks had elapsed after the operation, for by this time the deeper parts of the wound had become consolidated, and the capsule of the joint must have been closed. Had putrefaction occurred immediately after the operation, very disastrous consequences would doubtless have ensued. It must therefore be ever with a feeling of heary responsibility resting on himself that the surgeon undertakes such an operation.

Edinburgh.

\section{REPORT ON A PECULIAR MOUTH AFFEC- TION PREVALENT AMONG THE MEN OF THE INDIAN EXPEDITIONARY FORCE.}

\author{
BY GEORGE YEATES HUNTER,
}

SURGEON-MAJOR, TWENTY-SIXTH BENGAL NATIVE INFANTRY.

IT is difficult to identify this disease with any of the varieties of stomatitis hitherto described: probably it more resembles stomatitis membranosa, or, in some instances, stomatitis erythematosa, than others, although no false membrane is formed as in the former, and inflammation of the mouth, extending to the bowels, and causing diarrhoea, is not present as in the latter; nor is there salivation, though herpes labialis is not uncommon. Certainly the disease does not resemble stomatitis follicularis, nor, I think, can it be one of the many kinds of stomatitis fungosa, though, were it not for the absence of growth of tissue, I should be inclined to place it under that head; for I believe it to be a disease due to the grain used as food. The chief argument against diseased grain would appear to be the absence of diarrhoea; still, it should be borne in mind that the extension of the disease to the larynx is in favour of its being propagated by a vegetable parasite. The disease clearly is not stomatitis ulcerosa, nor can I trace any likeness to the three or four other kinds treated of; while, with regard to stomatitis syphilitica and stomatitis mercurialis, it is impossible to obtain reliable data, as the statements of natives on such points are not trustworthy. From a tabular statement, carefully prepared by Surgeon Clarkson, in which 83 cases are shown, it would appear that the troops suffered at the rate of 10 , and the camp followers at the rate of 15 per cent. The higher rate among the latter may be accounted for on the ground that they have not been, as a rule, so well fed and well cared for a body of men as the sepoys.

Symptoms.-At first slight elevation of the fungiform and filiform papillæ, followed by stripping or peeling off of patches of epithelium, chiefly in the middle of the dorsum of the tongue, until the membrane is almost denuded ; meanwhile fissures, mostly longitudinal, taking the direction in which the muscular fibres run, are noticed in nearly onethird of the total number of cases, and in about the same proportion the lips are sore; the labial, gingival, buccal, and palatal mucous membranes are also similarly affected. In half the number of cases the gums show a distinct blue line, or are bluish; and in two-fifths the gums are vlcerated at the point of junction with the teeth, while the teeth are loose. There is no pain in the mouth, neither is there feverishness, and the thermometer indicates no general rise of temperature, although a slight increase in the mouth itself is noted. As the disease of the mouth, fauces, and pharynx advances the laryngeal membrane in most instances becomes implicated; indeed, in the greater number of cases of 15 days' duration more or less hoarseness is present, and uneasiness on either side of the hyoid bone and thyroid cartilage, or pain and swelling in the submaxillary region, is almost invariably observed.

Causes.-Earth, air, and water would seem to be excluded as causes, for as regards all these elements, the disease commencing on board ship, together with there being no account of it as prevalent at Malta, put them out of the question. Doubtless the water, looking at the nature of the soil, is largely impregnated with lime, and it would be well to have it analysed ; still this would be too general a cause to assign for a disease affecting about 10 per cent. only of the men, to say nothing of its having made its appearance previous to the use of this water. Again, officers, who breathe the same air, drink the same kind of water, and are encamped on the same soil, are entirely exempt. To my mind the main point worthy of consideration in trying to discover its etiology is the fact that proportionately fourfold more cooking men suffer from the disease than non-cooking; this difference is, in my opinion, very striking. The former have lived in an exceptional manner, and are still doing so, since the cooking man on shore eats meat, vegetables, or fish curry-in short anything he can get, his diet being of a very varied character; whereas the non-cooking man has lived pretty much as usual, and, as contrasted with the cooking man, has been very much considered; in fact, what might almost seem a disqualification for employing him at all on foreign 